\title{
GIS APPROACH FOR PREVENTIVE EVALUATION OF ROADS LOSS OF EFFICIENCY IN HYDROGEOLOGICAL EMERGENCIES
}

\author{
M. Mangiameli, G. Mussumeci \\ Dept. of Civil and Environmental Engineering, University of Catania, Italy \\ (michele.mangiameli, g.mussumeci)@ dica.unict.it
}

KEY WORDS: GIS, Hydrogeology, Hazards, Decision Support.

\begin{abstract}
:
The theme of the simulation of hydrogeological risk with GIS technology is analyzed with focus on the modeling of the architecture of a Spatial Data Base to support risk analysis and on the construction of a specialized frame with free and open source software. For this purpose a model of analysis of the vulnerability of roads developed by (Cafiso et al., 2002) has been adopted. The case of study is represented by a seismic land characterized by steep slopes and frequent instability phenomena. In detail, the area of interest is a mountainous land in Sicily with a city, Enna (about 30.000 people), that lies on the top. The access to the city is assured by few and very winding roads which are also highly vulnerable to seismic and hydrogeological hazards. The loss of efficiency of these roads for exceptional rainfall events should compromise timeliness and effectiveness of rescue operations. The data of the sample area have been implemented in the specialized GIS appositely constructed in order to forecast the possible damage to roads and the results of some simulations have been related to the effects registered after some extreme events, obtaining useful indications for the validation of the approach.
\end{abstract}

\section{INTRODUCTION}

\subsection{The role of the road network in the emergency management}

In Italy the interest in the defense of the territory from landslides has certainly increased in recent years. From drought to torrential rains, Italy experienced a constant state of emergency, with an average of 68 floods and 138 landslides a year. This situation is linked to climate change, but also to the general poor protection of the environment, the unsustainable overbuilding, the few funds available to the bodies maintenance and inefficient territorial planning. In fact, the human activities are often characterized by a challenge against environment and the evolution of natural phenomena that ultimately jeopardizes the infrastructures and, most importantly, human lives.

When a calamitous event occurs, however, the role of the network infrastructures which play a function of "lifelines", (water or energy distribution systems and transport systems) is of primary relevance in emergency management (Maugeri et al., 2010; Condorelli et al., 2010). In particular, only the efficiency of the transport network infrastructures can assure the timeliness of rescue interventions (Cafiso et al. 2005, Cafiso et al., 2004).

If the damage and loss of functionality affecting road infrastructure are numerous and frequent, it is evident that proper planning of interventions in the field need a protection plan based in particular on the following aspects (Cafiso et al, 2002):

- identification of expected hazard scenarios and risk assessment;

- demarcation of areas at risk and adoption of safeguard measures that prevent the aggravation;

- development of systems for weather warning and alarm;

- adoption of emergency plans by the various Institutions involved in land management.

This paper deals with the hydrogeological risk in a seismic area characterized by a complex geomorphological configuration (Province of Enna, Enna municipalities). In this context, but in the general case of disastrous events, the timeliness and effectiveness of relief operations by the Civil Defense may be impaired by the loss of functionality of the access roads.

Our work deals with the prior analysis of the hazardous characteristics of the site and the vulnerability of the road infrastructures, in order to identify the critical issues and priorities, through the application of valuation models specially designed and developed. To the purposes of risk assessment, features of GIS have been proved extremely useful, since they allow automating the different stages of the procedure up to the production of thematic maps of interest.

\subsection{The GIS contribution to prevision, prevention and management of emergency}

The rescue operation, which can be defined as the set of operations to provide primary care to the affected population and to overcome emergencies, must also rely on advanced tools for managing information.

The aim is to coordinate the relevant institutional bodies in the implementation of the needed actions, ensuring timely and effectiveness. To process a so large amount of data it is necessary to activate, at the different scales of investigation and of administrative responsibilities, a GIS platform to dynamically manage the data and to obtain a real Decision Support System (Cafiso et al., 2001).

Land modeling in GIS environment allows to simulate probabilistic models the possible risk scenarios, so that the design and implementation of a full, effective and dynamic Geographic Information System is the starting point for planning the rescue actions, which are always strongly influenced by the time. Collecting and structuring of territorial data within a spatial database is the basis of a good operational organization, facilitating the preliminary estimation of the probable consequences of the calamitous event and giving support to decide "where" and "how" the available intervention teams and means can be used in the field to quickly restore normal living conditions of people.

An effective system of emergency management can be characterized by an architecture like that in Figure 1, where the data useful to the management of the risk scenario are collected 
and structured within a spatial RDBMS and linked to a GIS platform. The data, implemented and continuously updated, are suitably modeled and processed to simulate the phenomena and their consequences (e.g. the evaluation of damage to the buildings or the potential exposure of people) and to manage the emergency (e.g. searching for optimal paths for the achievement of the interested areas or the determination of escape routes on the basis of the travel time and the characteristics of the roads)..

Likewise, the proposed architecture allows continuous monitoring of risk areas and periodically check the functionality of the system in case of calamity. Because the land is subject to a continuous evolution, it is therefore necessary to provide continuous data collected and used for the system is always responsive to the status quo. Through this series of structured architecture proposal, it is possible to achieve the identification of hazard maps for the identification of areas where the risk is high and "Hazard Analysis and Critical Centre" (HACCP), i.e. the points where some action is urgently required. The structured system can thus plays the role of Decision Support System (DSS) for the institutional decision makers. (Figure 1).

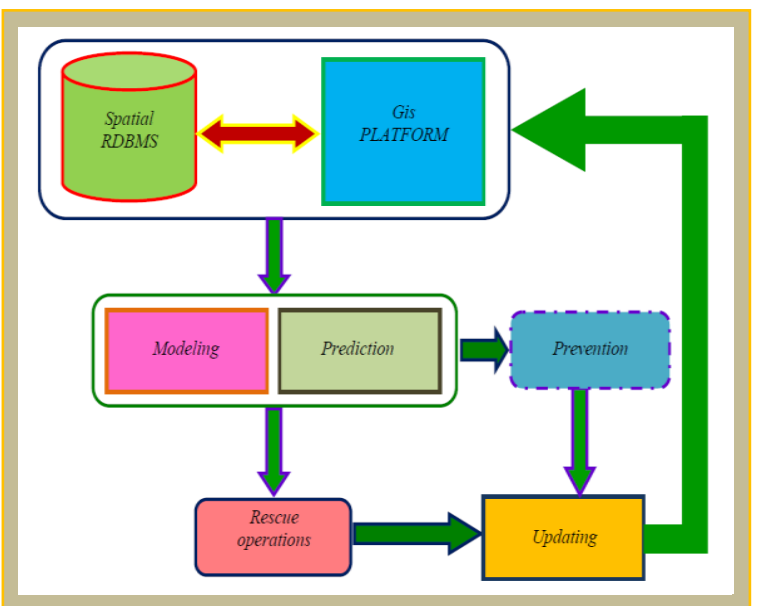

Figure 1. Architecture of a GIS-based DSS for emergency prevision and management.

\section{GIS APPPLICATION OF A METHODOLOGY FOR HYDROGEOLOGICAL RISK EVALUATION OF THE ROAD NETWORK}

The process of risk assessment due to a natural event consists of:

- the hazard assessment $H$, i.e. the probability that an exceptional event of a certain severity occurs in the area of interest;

- the exposure E, which consists of determining in quantitative and qualitative terms the various anthropogenic elements that characterize the area of interest, i.e. the number of the population, public services, infrastructure, buildings, and operating conditions, which can be damaged or destroyed by the event;

- the vulnerability $\mathrm{V}$, i.e. the propensity of infrastructure, people, goods and services to be damaged or modified as a result of an exceptional disaster.

\subsection{Hazard}

For the study area of this work, two hazard scenarios have been identified:
- landslide hazard;

- flooding, by identifying a hazard related to flood events, which can undermine individual hydraulic structures (bridges and culverts), and a hazard of water invasion of the roadway by water and debris.

More specifically, the geological and geomorphological hazards provide information on the expected movements and potential disruptions (Biondi et al., 2004). The hazard for flood events is related to the probability that an exceptional event occurs that leads to flooding or interference between the outflows of maximum flood and road infrastructure. In this case the value of hazard is associated to the tributary flow directly to the culvert, to which the tributary from bumps and ditches were added (if present). The hazard of invasion of the roadway has been determined considering that between two contiguous basins intersected by a road an area can be identified, within which the water particles do not flow in the culvert, but flow toward the road platform, having trajectories that do not lead the mouths of culvert (Figure 2).

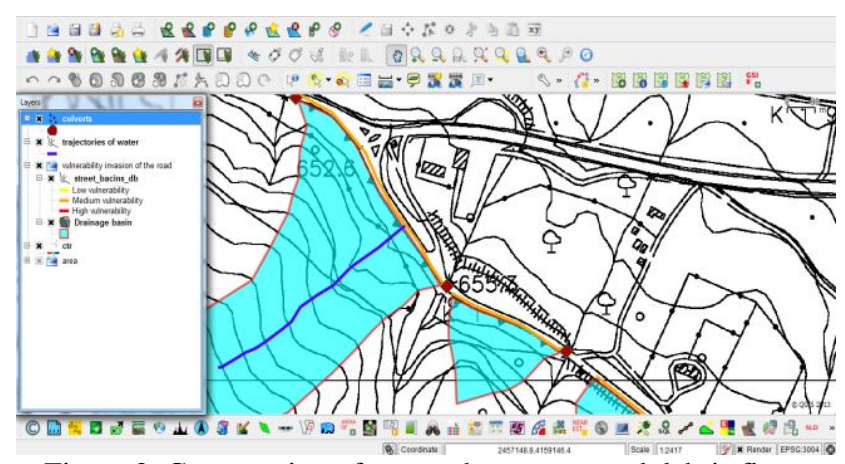

Figure 2. Construction of areas where water and debris flow directly over the road platform

In the absence of suitable channeling works, the runoff water, with the related transport debris, tends to invade the roadway, compromising the conditions of practicability.

To highlight which features are more susceptible to this phenomenon, the following Invasion Index of the road (Cafiso et al., 2002; Condorelli et al., 2007) has been adopted:

with:

$$
\mathbf{I}=\mathbf{Q} / \mathbf{L}
$$

$\mathrm{Q}=$ Water flow poured on the $\operatorname{road}\left[\mathrm{m}^{3} / \mathrm{s}\right]$;

$\mathrm{L}=$ Length of the road segment interested by the hazard of water invasion $[\mathrm{km}]$.

This coefficient is used to compare the potential danger for different road sections subject to the phenomenon, identifying three different levels of hazard (low, medium and high).

\subsection{Vulnerability}

The vulnerability can be related to the propensity of the infrastructure to suffer loss or reduction of functionality.

The vulnerability of a road is divided into:

- Vulnerability to landslides;

- Vulnerability to floods;

- Vulnerability to the problems of invasion of the roadway.

Vulnerability to landslides is assessed in terms of the propensity to suffer damage in relation to the potential instability of the soil. In this scenario, the elements of the vulnerability of a road are the type of road section and the presence of protection along slopes. Then an index of influence is defined, which takes into account the characteristics of the elements and defines their effect on the vulnerability of the 
road. Table 1 shows a possible criterion of assigning a level of risk, from $\mathrm{L}$ (Lower) to $\mathrm{M}$ (Medium) and $\mathrm{H}$ (Higher), by considering and combining the type of the cross-section with the presence and the type of the protection devices.

\begin{tabular}{|c|c|c|c|}
\hline \multicolumn{4}{|c|}{ Landslide Vulnerability " $V_{L}$ " } \\
\hline $\begin{array}{l}\text { PROTECTION } \\
\text { DEVICES }\end{array}$ & $\begin{array}{c}\text { Class of } \\
V_{L}\end{array}$ & $\begin{array}{l}\text { TYPE OF ROAD } \\
\text { SECTION }\end{array}$ & $\begin{array}{c}\text { Class of } \\
\mathbf{V}_{L}\end{array}$ \\
\hline $\begin{array}{l}\text { Retaining } \\
\text { Structures }\end{array}$ & $\mathbf{L}$ & $\begin{array}{c}\text { Bridge } \\
\text { Viaduct }\end{array}$ & $\mathbf{L}$ \\
\hline Protective Nets & M & $\begin{array}{c}\text { Embankment } \\
\text { (section in fill) }\end{array}$ & M \\
\hline No Protection & H & $\begin{array}{c}\text { Trench } \\
\text { (section in cut) }\end{array}$ & H \\
\hline
\end{tabular}

Table 1. Classification of the elements that combine to determine landslide vulnerability of the roads

The vulnerability to flood events is evaluated by considering the presence of culverts of section not suitable for disposal of the water coming from impluvia which can lead to a flooding of the road section (or even to its damage) in the presence of a high kinetic energy of the water. Therefore, for this estimate it is analyzed the maximum flow of water that can be disposed of. Instead, the vulnerability to invasion of the roadway is determined considering that the roadway can be invaded by water or debris in the absence of appropriate devices, such as ditches or gutters. Obviously for this estimate it is of particular importance the type of road section, since the sections in cut (trenches) or side-hill are more vulnerable than those in fill (embankment) or on viaduct. Then, in presence of a not-suitable design of disposal hydraulic works, it is easier that debris invade the roadway. Combining these characteristics of road sections and hydraulic devices, indexes of vulnerability to invasion of the road are determined with the above approach (Table 2).

\begin{tabular}{|c|c|c|}
\hline \multicolumn{3}{|c|}{ Water invasion Vulnerability " $V_{w}$ " } \\
\hline \multirow{3}{*}{$\begin{array}{l}\text { HYDRAULIC } \\
\text { DEVICES }\end{array}$} & $\begin{array}{c}\text { Culvert - Drainage } \\
\text { channel }\end{array}$ & $\mathbf{L}$ \\
\hline & Ditch & M \\
\hline & No device & $\mathbf{H}$ \\
\hline \multirow{3}{*}{$\begin{array}{l}\text { TYPE OF ROAD } \\
\text { SECTION }\end{array}$} & Embankment (in fill) & $\mathbf{L}$ \\
\hline & Hillside & $\mathbf{M}$ \\
\hline & Trench (in cut) & $\mathbf{H}$ \\
\hline
\end{tabular}

Table 2. Classification of the elements that combine to determine the vulnerability for water invasion

Combining the parameters of the upper tables we can synthesize the judgment of overall vulnerability of the road section to the specific hazard. For example, combining the nine possible couples of vulnerability associate to single elements, we can assign a class of vulnerability to each homogenous road segment. For example, assuming three classes, going from Low (L) to Medium (M) and High $(\mathrm{H})$, and giving higher weight to hydraulic devices respect to section typology, the classification of vulnerability is shown in Table 3 .

\begin{tabular}{|c|c|c|c|}
\hline \multicolumn{4}{|c|}{ Road vulnerability to water invasion "V ${ }_{\mathbf{W}}$ " } \\
\hline $\begin{array}{c}\text { HYDRAION TYPE } \\
\text { VULNERABILITY }\end{array}$ & \multicolumn{3}{|c|}{ VULNERABICVICE } \\
\cline { 2 - 4 } & L & M & H \\
\hline L & L & M & M \\
\hline M & L & M & H \\
\hline H & M & M & H \\
\hline
\end{tabular}

Table 3. Classification of road vulnerability to water invasion

\subsection{Exposure}

The exposure is related to the extension of the areas and anthropic systems, which, falling in a territorial scope of established danger, are susceptible to damage due to the occurrence of the event. In particular, the elements exposed are people, strategic buildings, structures of civil protection, transport infrastructures.

For this type of analysis, it is useful to assess the concentration of population in different times and on different days of the week in order to estimate the approximate number of human lives that could be at risk (Figure 3).

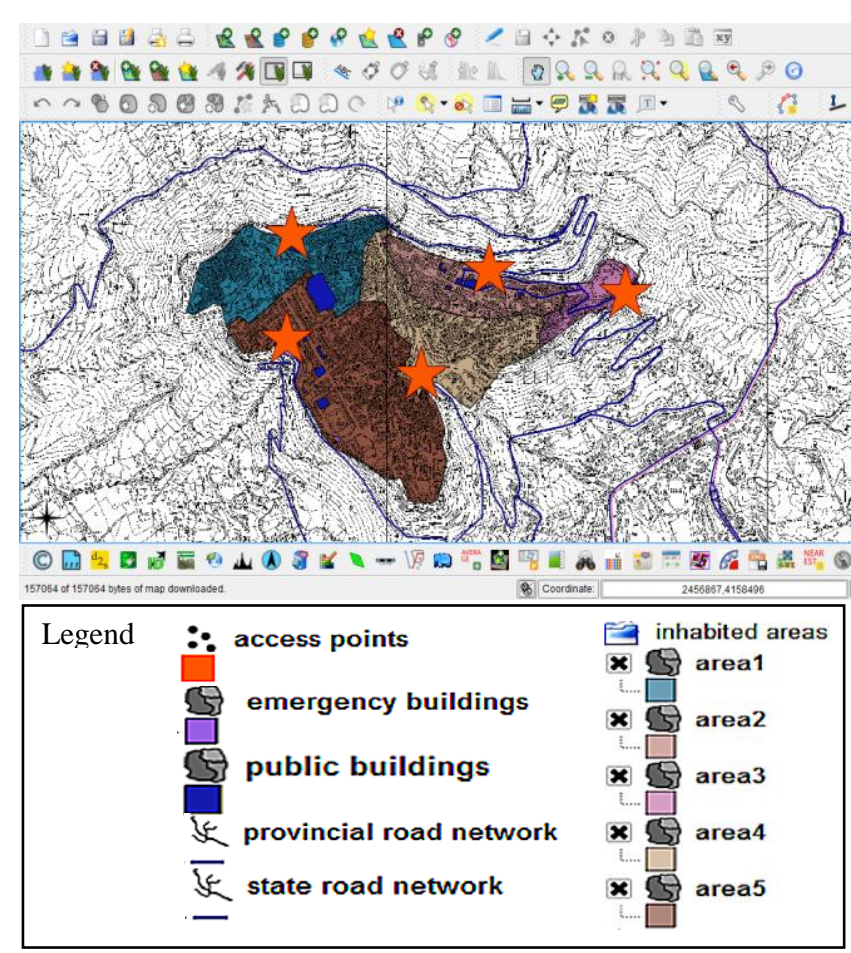

Figure 3. Classification of people exposure and points of access to the town

\subsection{Risk evaluation}

The relation used for the calculation of the risk of each road section is of the type

$$
\boldsymbol{R}=\boldsymbol{H} \times \boldsymbol{E} \times \boldsymbol{V}
$$

The risk is therefore determined by the combination of the values of hazard, exposure and vulnerability.

We addressed each risk scenario in a separate way, i.e. the hydrogeological risk in the road network, risk of the geological instability and risk of the road network due to the risk of floods. Moreover, we defined three classes for each scenario of risk: low (L), medium (M) and high (H). 


\section{DESIGN AND IMPLEMENTATION OF A RDBMS TO SUPPORT GIS PLATFORM FOR THE EVALUATION OF ROADS LOSS OF EFFICIENCY IN HYDROLOGICAL EMERGENCIES}

An efficient and effective architecture for risk assessment is characterized by a database that contains all the data collected and updated to assess the hazard, exposure and vulnerability in the area of interest. In particular, the database must have a spatial feature in order to be able to manage data that are georeferenced on the ground (Pirotti et al., 2011). Moreover the data structure must be designed according to a relational logical modelling to manage within the GIS platform different types of geometric information, spatial relationships, topological relations, directional relations and proximity relations (Scianna et al, 2007, Famoso et al., 2012).

All environments allow the management of a GIS database and therefore of spatial data, but since some GIS software are born without DBMS support, the functions related to the management of the data can be limited. The direct management of data in GIS software can lead to anomalies within the database as data redundancy and inconsistency (Pirotti et al., 2011), problems of competition for access to data by multiple simultaneous users, loss of data integrity, security problems, and problems of efficiency from the point of view of data search and update. This determines the impossibility of developing a relational database. For this reason, in a complete and efficient design of a GIS, external Relational Database Management
Systems (RDBMS) are used for the management of spatial database containing the data used in the GIS application (Mangiameli et al., 2011).

The software technology used in this work is totally free and open source. The Desktop GIS software used are GRASS and QGIS, while Mapserver with the application pmapper was used as web-gis platform and PostgreSQL with the spatial Postgis as RDBMS. Figure 4 shows with the Unified Modeling Language (UML) the application domain of the platforms, the structure of the architecture and software versions used.

The hardware architecture used for the DBMS is outside the GIS platform. In this case the server is in the same machine where the DBMS and the spatial database are located, while all GIS applications (Desktop and Web) are available on an external PC. With this architecture, all the characteristics of DBMS and database are exploited (Pirotti et al., 2011), and the speed for updating the database modification and query is improving, thanks to a totally dedicated machine (Figure 5).

The design of the data structure to be implemented within the RDBMS has followed three main phases:

1.the identification of the entities involved in the scenario of hydrogeological risk assessment;

2.the relationships between the entities previously identified; 3.the conceptual design of the data structure (Figure 6);

4.the physical implementation of the data structure within the spatial RDBMS.
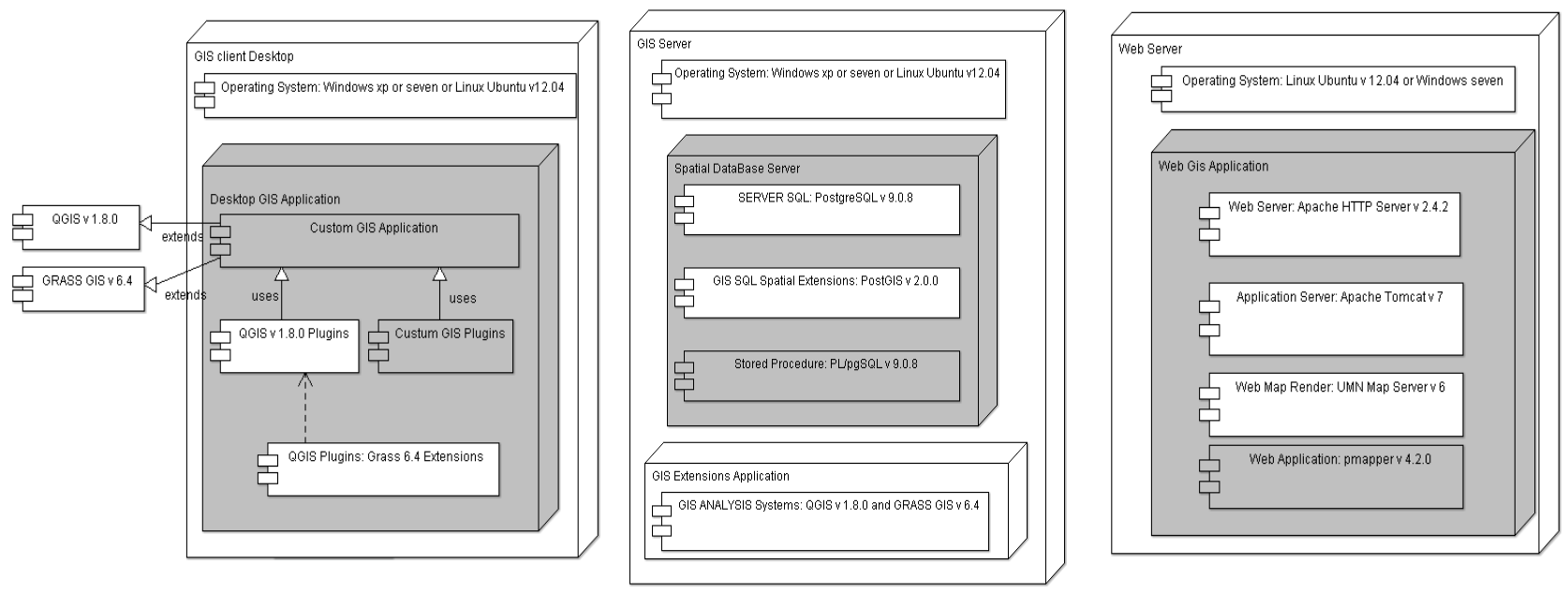

Figure 4. Deployment diagram related to GIS applications

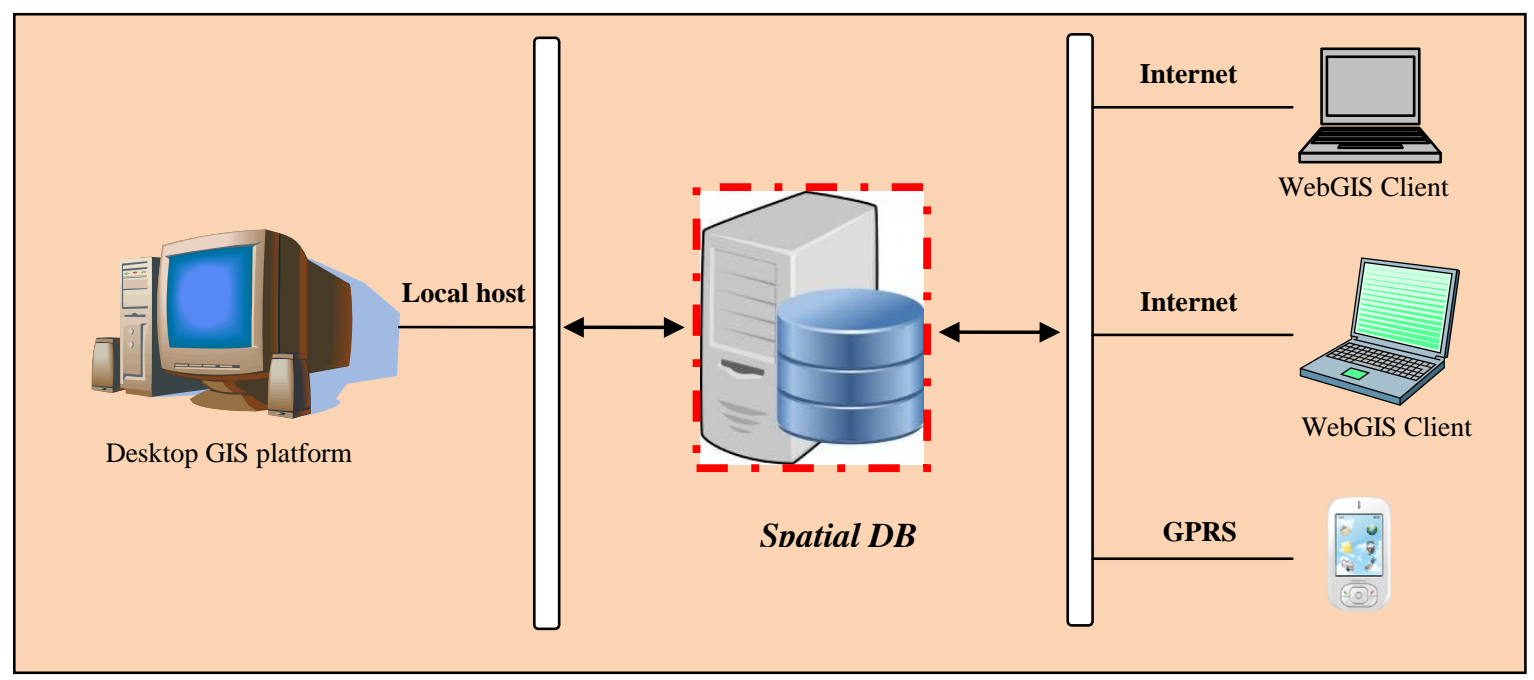

This contribution has been peer-reviewed. doi:10.5194/isprsarchives-XL-5-W3-79-2013 
Figure 5. The hardware architecture where the spatial database is located in a dedicated server.

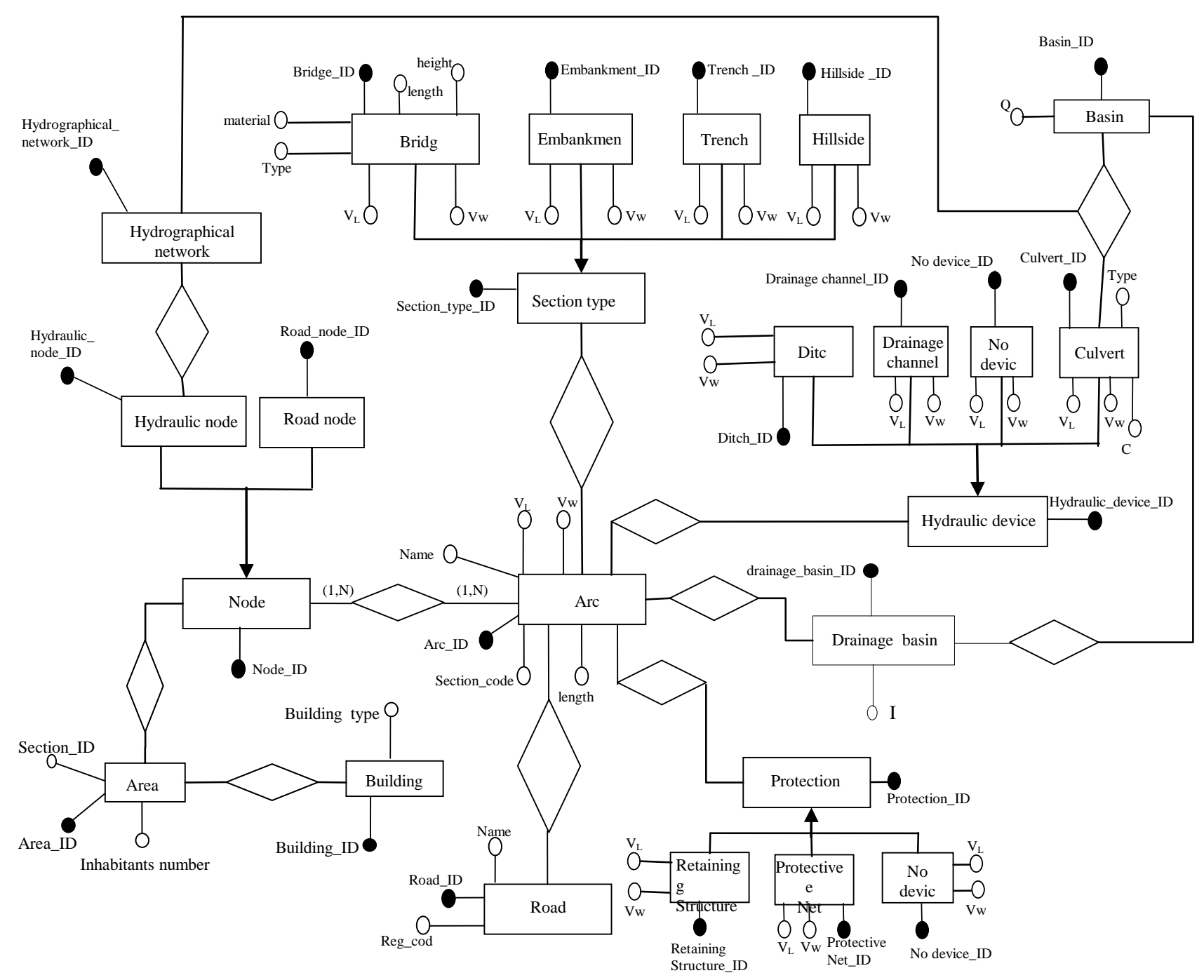

Figure 6. Simplified E-R diagram relating to the conceptual design of the data structure proposed

The first entity considered is the access road network to the area of interest. In the translation to the logical model and to the final physical structure of the DB, the entity Arc is characterized by the following attributes: Road_ID, Name, Section_code, Section type_ID, length, Protection_ID, Hydraulic device_ID, Vulnerability to water invasion $\mathrm{V}_{\mathrm{L}}$, and Vulnerability to landslide $\mathrm{V}_{\mathrm{L}}$.

With respect to the architecture arc-node of the road graphs, the entity Arc is the entity related to Node (Figure 6). This latter entity contains the attributes Node_ID and Node_type.

Every single arc of the road network is characterized by a type of section (Bridge, embankment, hillside and trenchs), and can have protection systems and/or hydraulic devices. For this reason, in the proposed data structure, the entity arc is related to the entity section_type by using Section_type_ID as foreign key and to the entities protection, by the foreign key
Protection_ID, and hydraulic devices by the key hydraulic dev_ID.

Hydraulic device and Protection work entities are characterized by own class of vulnerability (Tables 1 and 2) and are connected to the entity arc, so that it is possible to automatically determine the class of vulnerability for each possible couple of cross-section and protection or hydraulic devices.

For the hazard assessment, it is necessary to analyze the entities involved in the geological hazard, in the hazard for flood events and in the hazard related to the water invasion of the roadway. The geological hazard is represented by a polygonal thematism called geological areas, characterized by the attributes $I D \_$area, typology and slope. In this way the different levels of geological hazard can be classified.

The hazard for flood events, in its generic expression, is a thematism of punctual type. This thematism can be 
automatically generated in GIS environment using tools of hydrological modelling in GRASS to construct the hydrogeological reticulum from a DTM and by intersection with the road network. Its attributes are: Basin_ID, flow rate of maximum full $(\mathrm{Q})$, coefficient of escorrentia (C), and the estimated flow rates in the assigned return periods (i.e. $\mathrm{Q}_{50}$, $\mathrm{Q}_{100}, \mathrm{Q}_{200}$ ).

The relationship with the road is represented by the attribute Arc_ID.

For the assessment of the hazard to invasion of the road the entity involved is the drainage basin (Figure 6) which is related to the Arc entity and is represented by a polygonal thematism where the degree of hazard is expressed by the value of the Invasion Index (I).

For the exposure evaluation of the area of interest, we implemented in the data structure the relation between the exposed areas and the road infrastructures of access (Figure 6). The data to populate the table of the Area entity may be provided by the electoral office of the municipality, thus obtaining an efficient source of information on the number of people living in an area. The entity Area is characterized by the attributes Area_ID, Section_ID (that indicates the electoral sections present in an area), Inhabitants number (that indicates the number of resident people), and it relates to the entity Nodes to identify the access nodes to the area. The entity Building is a polygonal theme with the attributes Building_ID and Building type, that contains information on the type of the building (hospital, civil protection structure, school, etc.).

The number of inhabitants has been used to assign the exposure class to the roads afferent to the access nodes to each area using the following criteria (Vicari, 2001; Cafiso et al. 2002):

- the roads that directly reach the access points to the city assume an exposure equal to that of the area served;

- for the successive ramifications, the exposure is divided in equal parts.

The exposure is represented via a polygonal thematism, served by one or more roads, to which is associate a class of exposure based on the number of the inhabitants, thus identifying three exposure levels: low (L), medium (M) and high (H).

The hydrological vulnerability of road infrastructures is understood as the propensity to miss the functional efficiency in disaster, so the transport network do not meet the mobility needs. For an accurate assessment of the vulnerability of road infrastructure, it is necessary to analyze for each arc the following aspects: vulnerability to instability, vulnerability to flood events and vulnerability to problems of invasion of the roads. The assessment of the index of vulnerability on the instability is obtained in a GIS environment by selecting from the entity Arc the typology of cross-section (Bridge, Embankment, hillside and trench) and the associated class of vulnerability. Three classes of vulnerability are defined for each single arc, so the vulnerability_instability will be a thematism of linear type.

For the evaluation of the vulnerability to flood events, the culvert entity is taken into account. This is referred to as punctual vulnerability of the road section defined by the maximum flow rate value that can be disposed of. Similarly the other cases, three classes of vulnerability to flood events are determined for the section of the road: Low, Medium, High. Therefore the thematism flood_events_vulnerability is characterized by a punctual geometry.

The vulnerability to water invasion is a thematism of linear type (invasion_vulnerability) obtained by intersecting the thematism drainage basin with the Arc theme. Subsequently, using the query builder on the previous selection, it have been identified the road sections that differ by section typology and the hydraulic works contained.

Finally, the hydrogeologic risk of each arc of a road can be calculated in GIS environment as:

$$
\mathrm{R}=\mathrm{H} \times \mathrm{V} \times \mathrm{E}=\mathrm{D} \times \mathrm{E}
$$

Therefore, in the implemented GIS three thematic maps are obtained, one for each hazard scenario. For a first simulation of the methodological approach we can assume, simplifying the case study, three different levels: Low(L), Medium(M), $\operatorname{High}(\mathrm{H})$.

The first step is the construction of the damage matrix through the intersection of Hazard and Vulnerability classes (table 4).

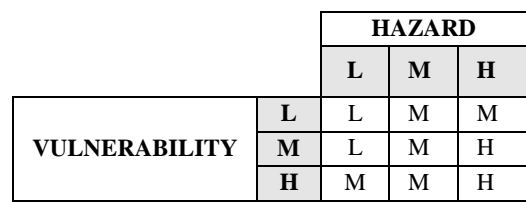

Table 4. Damage matrix

Then, the intersection of Damage and Exposure gives the final classification of risk for each road segment (table 5).

\begin{tabular}{|c|c|c|c|c|}
\cline { 3 - 5 } \multicolumn{2}{c|}{} & \multicolumn{3}{|c|}{ EXPOSURE } \\
\cline { 3 - 5 } \multicolumn{1}{c|}{} & L & M & H \\
\hline \multirow{3}{*}{ DAMAGE } & L & L & M & M \\
\cline { 2 - 5 } & M & L & M & H \\
\cline { 2 - 5 } & H & M & M & H \\
\hline
\end{tabular}

Table 5. Risk matrix

In the GIS the risk of geological instability of the roads is obtained by intersecting the thematism instability_vulnerability with the areas characterized by three classes of geological hazard resulting in the vector thematism damage. From a further intersection of this thematism with the exposure vector, we obtained the linear vectorial thematism relative to the roads. The risk of flood events is a punctual thematism because the analysis for its determination refers to the maximum expected flood flows with assigned return periods and the maximum flow rates that can be disposed of by culverts. Intersecting the punctual thematism flood_events_ hazard with the flood_events_vulnerability, the punctual vectorial thematism damage is obtained. This value is then intersected with the thematism exposure. The risk analysis so identifies the road sections where there may be situations of danger in occasion of exceptional flow rates due to the presence of culverts with hydraulic section not suitable.

The risk of water invasion is a linear thematism obtained by intersecting the linear thematism invasion_vulnerability with the thematism invasion_hazard, thus obtaining the matrix of the damage. Successively, intersecting the vector damage with the thematism exposure, we can produce the linear thematism that identifies the road arcs involved.

\section{CASE STUDY}

The GIS platform has been tested on the road network within the territory of a town, Enna, situated in the central part of the Sicilian territory at an altitude of over 900 meters, on the top of a mountain. The territory is geomorphological rugged and presents slope values even higher than $35 \%$, with widespread problems of stability, except for the south-east side. 
The morphological analysis of the territory was carried out managing with standard GIS functionalities a regional technical cartography at 1:10.000 scale and a 2-meter DTM imported from a WMS of the Sicilia Region. Very useful, specially for data updating, has been the Bing image with label acquired with the plugin OpenLayers provided from QGIS (Figure 7).

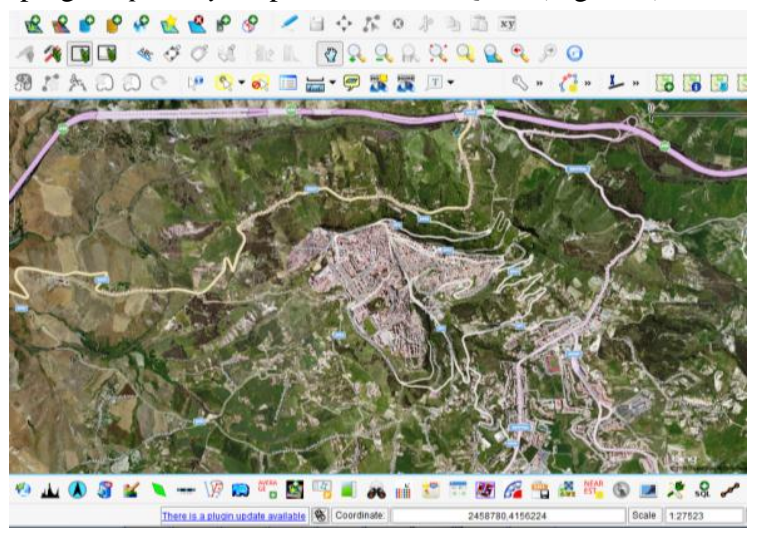

Figure 7. Road infrastructures of Enna

The landslides and erosion interesting Enna adverts to instabilities, i.e. unstable equilibrium phenomena affecting both more superficial and deeper zones of the soil, including phenomena of intense erosion with real mass movements, in addition to landslides caused by earthquakes. The hydrography of the territory is characterized by several watersheds of erosive nature, but limited in flow rate. The most important one is the Torcicoda, that collects rainwater and wastewater of the city, flowing in the Sasso river. From an historic analysis, these streams showed no overflow problems, but along the roads that connect the city of Enna, phenomena of surface runoff are frequent, with flow values able to affect the functionality of the road network. The main roads that provide access to the city are: provincial roads SP 28, SP 2 and highway SS 121 on the North; SS 127 bis, SP 1, SP 51 on the East; SS "Monte Cantina", SP 29 on the South; SP 81 on the west. This thematism has been scanned into QGIS environment and managed using the support of an external Postgresql database with the PostGIS extension. To analyze the hydrogeological risk that can involve the road infrastructure in the territory of Enna, we started with the evaluation of the hazard. In particular, two hazard scenarios have been simulated:

- the occurrence of landslides;

- the occurrence of floods events.

In the implemented GIS, the geological hazard is represented by a vector thematism based on the variation of slope values of the soil (Figure 8).

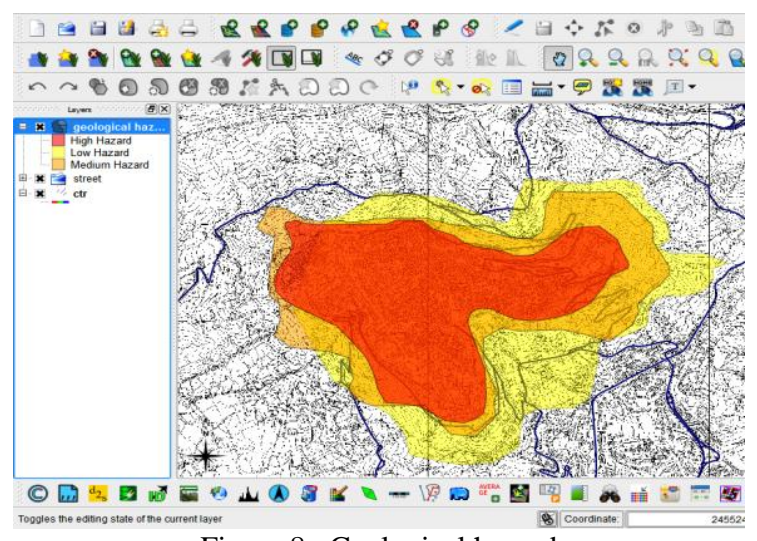

Figure 8. Geological hazard
To evaluate and represent in the GIS the hazard for flooding events we adopted a punctual thematism, obtained with the intersection between roads and hydrographic network, that reports the flow rate of the culverts, if it's present, and the water flow coming from the basins.

For the hazard of water invasion of the roadway, we identified, along each road, the areas within which the water particles do not flow in the watershed but directly over the roadway and that we call "drainage basins". Intersecting the drainage_basins and the Arc themes, we individuated the road segments which may be affected by the invasion in the absence of hydraulic devices. Moreover, for each arc, we calculated the index of invasion $\mathrm{I}$ in order to prioritize and compare different road sections subject to this phenomenon. In particular, we identified three hazard classes, as shown in Figure 9.

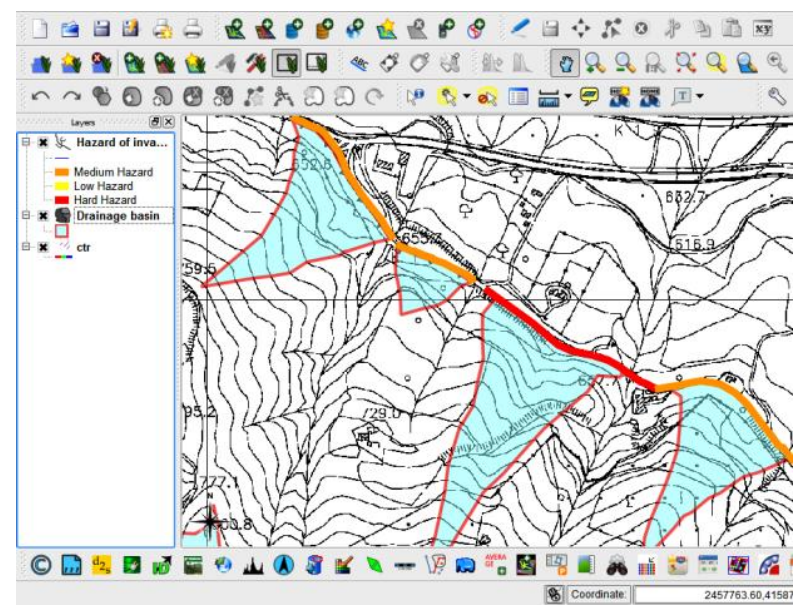

Figure 9. Hazard of water invasion of the roadway

About the exposure, we considered the resident people and the anthropic elements of strategic interest, like public buildings and emergency facilities taking into account only the area of "Enna Alta". We implemented the five areas identified according to the five access nodes connected with the road network and assigned a class of exposure based on the number of inhabitants (Cafiso et al., 2002).

The vulnerability, intended as the loss of efficiency of the road infrastructures, was evaluated once again taking into account the instability due to rock falls and landslides, flood events and vulnerability to invasion road. For the analysis of vulnerability to instability, we selected the individual road sections characterized by the attributes section_type and protection. Thus, based on the corresponding class of vulnerability, we automatically identified the three classes of vulnerability to landslides (Figure 10). 


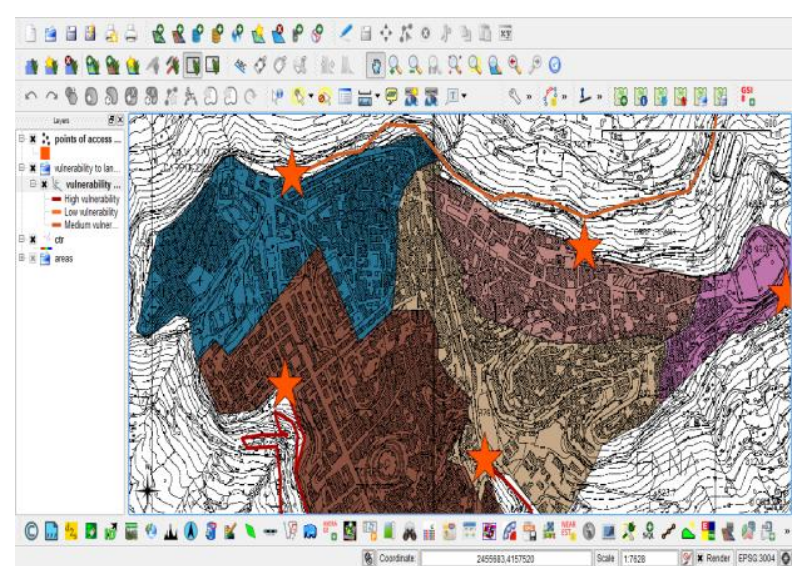

Figure 10. Road vulnerability due to soil instability

To estimate the vulnerability to flood events, we considered the culvert entity characterized as punctual geometry. A section not suitable for the disposal of water coming from watershed can lead to a flooding of the road section. To evaluate the vulnerability of the road segment, we calculate the ratio between the flow rate of the basin and the flow rate of the road section, and, using the classification proposed by (Cafiso et al., 2002) we automatically obtained the classification and its graphical representation based on typical functionalities of GIS environment (Figure 11).

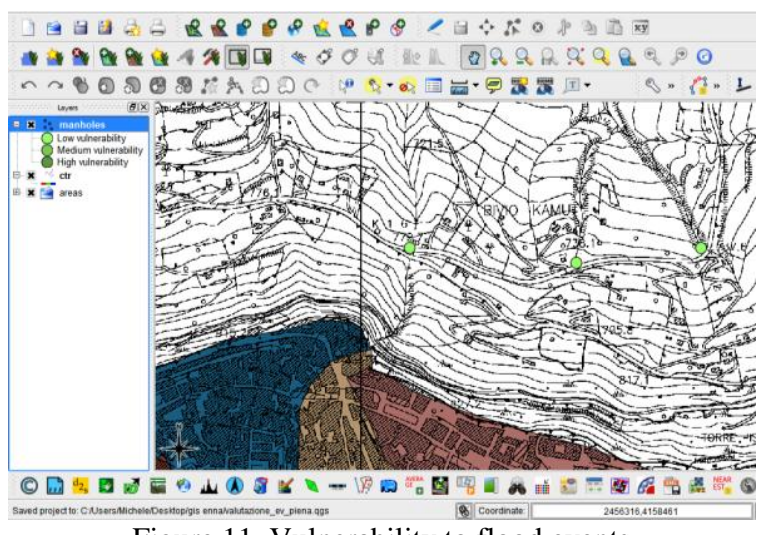

Figure 11. Vulnerability to flood events

The assessment of the vulnerability to water invasion was obtained by intersecting the drainage_basin theme with the Arc theme and, successively, using the query builder on the previous selection, we identified and classified the road segments for type of section and hydraulic devices.

Finally we can determine the hydrogeological risk in the road network by overlapping the data related to hazard hazard of water invasion, vulnerability to water invasion and exposure. Obviously, combining the hazard with the vulnerability it is possible to determine the expected damage on the elements of interest.

The classification of the risk is then carried out by a qualitative point of view to obtain, for each scenario, the areas at low, medium and high risk. In the risk assessment more weight is given to the exposure in order to highlight the importance of the human factor with respect to the economic one.

The risk on the geological instability of the roads is obtained by intersecting the linear theme of the vulnerability to geological disruption with the areal theme of the geological hazard, obtaining the damage theme. From a further intersection of this theme with the exposure one, we obtained the linear theme of the risk of the roads due to geological instability (Figure 12).

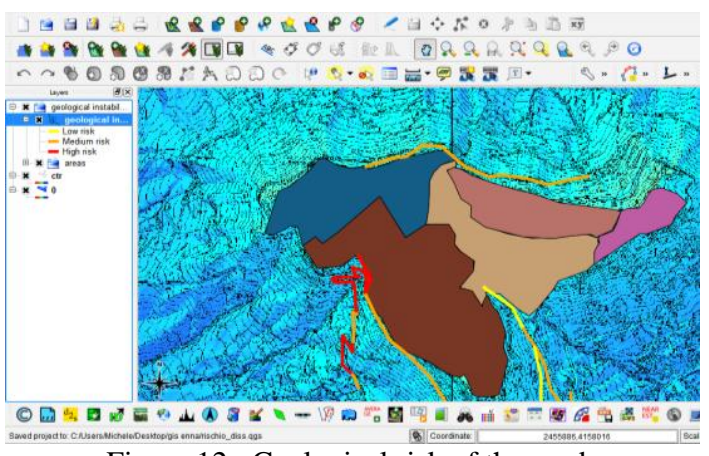

Figure 12. Geological risk of the roads

With the same approach, we obtained the mapping of the risk to flood events and of water invasion of roads.

Finally, it is possible to show the overall view of risk along the roads of interest (Figure 13).

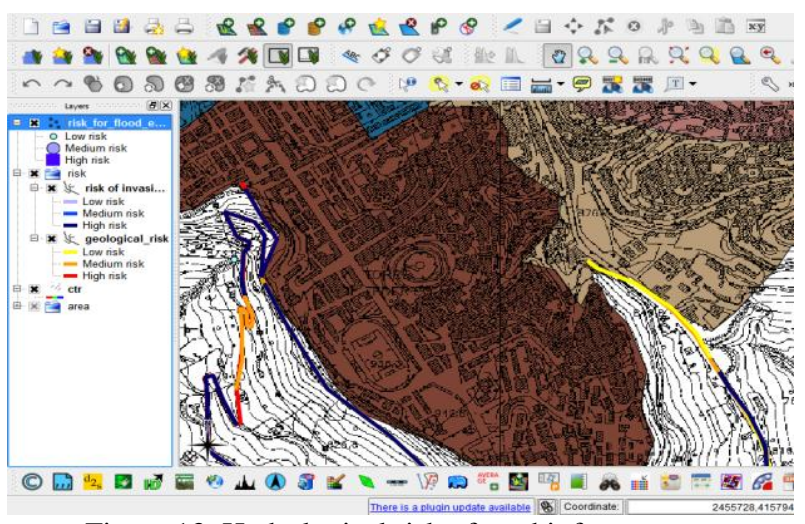

Figure 13. Hydrological risk of road infrastructure

\section{CONCLUSIONS}

For the emergency management and in particular when hydrogeological disasters occur, all the transport systems and especially the road infrastructures play a important role of "lifelines", in order to ensure a quick access to the areas affected by the event and provide relief to people. It is thus necessary to guarantee a minimum level of efficiency of the roads. With the present work, we propose a methodological approach for the design and realization of a GIS platform finalized to the implementation of a qualitative or analytical model for evaluating the hydrogeological risk along road infrastructures. To this end, particular attention has been paid to the design of the database structure in order to relate the various entities involved and make possible to automate various phases of the risk analysis, producing digital and queryable thematic maps and thus facilitating the risk assessment and the definition of a prioritization of the interventions to reduce the risk of a loss of functionality of the road network. The entire platform has been constructed using only free and open source software.

\section{References from Journals:}

Cafiso, S., Cutrona, G., Mussumeci, G., 2002. Idrogeologia e rischio stradale nella gestione del rischio a Enna. Aspetti metodologici e operativi nell'analisi del rischio con il GIS. Geomedia 4, pp. 6-14 
Famoso, D., Mangiameli, M., Roccaro, P., Mussumeci, G., Vagliasindi, F.G.A., 2012. Asbetiform fibers in the Biancavilla site of national interest (Sicily, Italy): review of environmental data via GIS platforms. Reviews in Environmental Science and Bio-technology.

Pirotti, F., Guarnieri, A., Vettore, A., 2011. Collaborative WebGIS design: a case study for road risk analysis and monitoring. Transactions in GIS 15(2), 213-226.

Scianna, A., Cernigliaro, F., 2007. Metodologia GIS per la valutazione ambientale strategica, Geomedia 3.

\section{References from Books:}

Cafiso, S., Condorelli, A., Mussumeci, G., 2005. Functional analysis of the urban road network in seismical emergency. GIS application on Catania city. In: Seismic prevention of damage. A case study in a Mediterran city. (Serie: Wit Transaction on State-of-the-art in Science and Engineering). vol. 8, p. 393-408, WITpress, ISBN: 1-84564-004-7

Condorelli, A., Mussumeci, G., 2010. GIS procedure to forecast and manage woodland fires. In: M. Konecny, S. Zlatanova, T.L. Bandrova Eds. Geographic Information and Cartography for Risk and Crisis Management. Towards better solutions. p. 103111, Berlin, Heidelberg, Springer, ISBN: 978-3-642-03441-1, doi: 10.10007/978-3-642-03442-8

Biondi, G., Condorelli, A., Maugeri, M., Mussumeci, G., 2004. Earthquake-triggered landslide hazard in the Catania area . In: Risk Analysis IV. WIT Transactions on Ecology and the Environment, vol. 77, p. 115-130, WIT Press, ISBN: 1-85312736-1, ISSN: 1743-3541, doi: 10.2495/RISK040111

Maugeri, M., Motta, E., Mussumeci, G., Raciti, E., 2010. GIS Techniques in the Evaluation of Pipeline Network Seismic Hazard. In: M. Konecny, S. Zlatanova, T.L. Bandrova Eds. Geographic Information and Cartography for Risk and Crisis Management. Towards better solutions. p. 143-154, Berlin, Heidelberg, Springer, ISBN: 978-3-642-03441-1, doi: 10.10007/978-3-642-03442-8

\section{References from Other Literature:}

Condorelli, A., Mussumeci, G., Siligato, G., Storaci, C. 2007. Un SIT tematico per la modellazione del rischio idrogeologico. In: Convegno Nazionale SIFET 2007 "Dal rilevamento fotogrammetrico ai database topografici", SIFET, ISBN: 88901939-4-8, Arezzo, 27-29 giugno 2007

Cafiso, S., Colombrita, R., D'Andrea, A., Mussuumeci, G., Colombrtita, F., Condorelli, A., 2001. Un modello di GIS per la valutazione del rischio sulle infrastrutture stradali nelle emergenze della protezione civile, pp. 1-170. In: Atti XI Convegno Nazionale della Società Italiana di Infrastrutture Viarie (SIIV).

Mangiameli, M., Muscato, G., Mussumeci, G., 2011 b. Creazione e gestione dinamica di un geo-database da piattaforma Web-GIS open source. In: Geomatica: le radici del futuro. Tributo a Sergio Dequal e Riccardo Galetto. p. 45-48, Torino-Pavia:Edizioni SIFET, ISBN: 88-901939-6-4

Cafiso, S, Condorelli, A., Cutrona, G., Mussumeci, G., 2004. A seisismic network reliability evaluation on GIS environment. A case of study on Catania province. In: 4th International Conference on Computer Simulation in Risk Analysis and Hazard Mitigation Rhodes. Rhodes (Greece), 27 - 29 September 2004
Mangiameli, M., Muscato, G., Mussumeci, G., 2011. Creazione e gestione dinamica di un geo-data base da piattaforma web-gis open source. Geomatica le radici del futuro, pp.45-48.

Vicari, M., 2001. Definizione della Banca dati geograficoterritoriale e analisi del rischio idrogeologico sul Sistema Stradale della Città di Enna, Tesi di Laurea, Università degli Studi di Catania (Relatori Cafiso D., Mussumeci G.). 